\title{
A LONG-TERM STUDY OF MANAGEMENT OF 36 CASES OF RECURRENT ANTERIOR SHOULDER DISLOCATIONS IN OSMANIA GENERAL HOSPITAL, HYDERABAD BY MODIFIED BOYTCHEV PROCEDURE DURING MAY 1995 TO MAY 2015 - A PROSPECTIVE STUDY
}

\author{
V. S. Ravindranath', M. Sri Rangarao ${ }^{2}$, K. Nagamuneendrudu ${ }^{3}$, Kishore4, V. L. Sravanthi ${ }^{5}$
}

${ }_{1}$ Professor-In-Charge, Department of Orthopaedics, Osmania General Hospital/Osmania Medical College, Hyderabad, Telangana. ${ }^{2}$ Assistant Professor, Department of Orthopaedics, Osmania General Hospital/Osmania Medical College, Hyderabad, Telangana. ${ }_{3}^{3}$ Associate Professor, Department of Orthopaedics, Osmania General Hospital/Osmania Medical College, Hyderabad, Telangana. ${ }^{4}$ Senior Resident, Department of Orthopaedics, Osmania General Hospital/Osmania Medical College, Hyderabad, Telangana. 5Junior Resident, Department of Orthopaedics, Osmania General Hospital/Osmania Medical College, Hyderabad, Telangana.

\section{ABSTRACT}

\section{BACKGROUND}

The purpose of this study is to evaluate results of the Modified Boytchev procedure for recurrent anterior dislocation of the shoulder in 36 patients in Osmania General Hospital (OGH) under Osmania Medical College (OMC), Hyderabad, Telangana, during May 1995 to May 2015.

\section{MATERIALS AND METHODS}

36 patients were followed in the Teaching Hospital, OGH, at regular intervals. Pain and Functional assessments were done. The mean number of redislocations was 1 . Outcome was evaluated using the Burkhead and Rockwood criteria. ${ }^{1}$

\section{RESULTS}

The mean follow-up period was 20 yrs. Outcome was excellent in 35 patients. One patient had recurrent dislocation.

\section{CONCLUSION}

The Modified Boytchev procedure is a simple and an easily reproducible surgical treatment for Recurrent Anterior Shoulder dislocation with proper exclusion criteria. It is also very cost effective procedure.

\section{KEYWORDS}

Coracoid Osteotomy; Anterior Shoulder Dislocation, Modified Boytchev.

HOW TO CITE THIS ARTICLE: Ravindranath VS, Rangarao MS, Nagamuneendrudu K, et al. A long-term study of management of 36 cases of recurrent anterior shoulder dislocations in Osmania General Hospital, Hyderabad by modified Boytchev procedure during May 1995 to May 2015 - a prospective study. J. Evolution Med. Dent. Sci. 2017;6(12):939-943, DOI: 10.14260/jemds/2017/201

\section{BACKGROUND}

The shoulder joint is less constrained joint due to large spherical head and small glenoid, the stability of the joint depends mostly on the capsule and the glenohumeral ligaments and the rotator cuff, biceps tendon and the force couple caused by the deltoid and the rotator cuff, unlike hip joint which is also multiaxial joint and very stable inherently; the shoulder is prone for dislocation and is at high risk of recurrent anterior dislocation, more so in athletes with overhead activity and anybody uses the shoulder for over the head activities. Surgical treatments for recurrent anterior dislocation of the shoulder include passive interventions using capsuloligamentous or bone block to create barriers and active interventions using muscle action. Major disadvantages of these treatments are long immobilisation and loss of external rotation of shoulder. The Modified Boytchev procedure ${ }^{2}$ can overcome these disadvantages by re-routing the coracoid process with its attached conjoined tendon of the short head

Financial or Other, Competing Interest: None.

Submission 12-07-2016, Peer Review 18-08-2016,

Acceptance 23-08-2016, Published 09-02-2017.

Corresponding Author:

Dr. V.S. Ravindranath,

Plot No: 50, Srinivasa Colony (West),

S. R. Nagar,

Hyderabad- 500038, Telangana.

E-mail: vsravindranath@rediffmail.com

DOI: $10.14260 /$ jemds $/ 2017 / 201$ of the biceps and coracobrachialis with the pectorals minor muscle deep to the subscapularis muscle and re-attachment to its anatomic location. It was then Modified ${ }^{3}$ by rerouting the conjoined tendons of the short head of biceps and coracobrachialis only.

\section{MATERIALS AND METHODS}

The study was done at a teaching hospital, Osmania General Hospital, Hyderabad during May 1995 to May 2015; 36 patients were followed at regular intervals for 20 years after being assessed by clinical examination, MRI studies of the joint and for pain and functional scores using Burkhead and Rockwood criteria. ${ }^{1}$ All patients had Bankart's lesion.

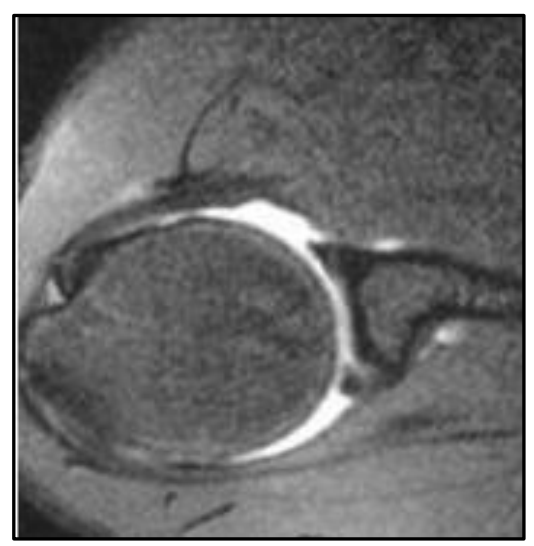

Figure 1: Bankart's Lesion 


\section{Inclusion Criteria}

1. Young and active patient.

2. Recurrent dislocation.

3. Post-traumatic dislocation.

4. Strong subscapularis muscle, ${ }^{4}$ i.e. a thick anterior axillary fold and assessed by abdominal press test.

\section{Exclusion Criteria}

1. Old sedentary patients.

2. Rotator cuff tears.

3. $\quad$ Old 4 or 3 part fracture proximal humerus.

4. Habitual dislocation.

5. Epileptic patient.

\section{Surgical Procedure}

Patients were placed in a supine position under General anaesthesia and a sand bag was placed under the medial border of the scapula (Fig. 2). C-arm to be positioned from the same side from cephalic direction (Fig. 3). The standard deltopectoral approach was used (Fig. 4). The anterior margin of the Deltoid was exposed, while the Pectoralis Major was retracted medially to expose the horizontal part of the coracoid process that was the tendinous origin of the short head of the biceps and coracobrachialis. The tip of coracoid process was identified. An anteroposterior pre drill hole was made in the coracoid process along its long axis. The tip of the coracoid process along with the origin of short head of biceps and coracobrachialis was osteotomised and moved distally (Fig. 5). With the shoulder in internal rotation, a plane was developed between the joint capsule of shoulder and the subscapularis muscle starting just proximal to the lower border of the subscapularis without injuring the leash blood vessels at the lower border of subscapularis muscle (Fig. 6). Care was taken not to damage the anterior circumflex humeral vessels. The detached tip of the coracoid process along with the attached muscles was passed through the plane and fixed to the predrilled proximal counterpart of the coracoid process using a $3.5 \mathrm{~mm}$ AO cancellous screw (about $25 \mathrm{~mm}$ in length), while the arm was maintained in internal rotation (Fig. 7 and 8). After haemostasis, the wound was closed in layers.

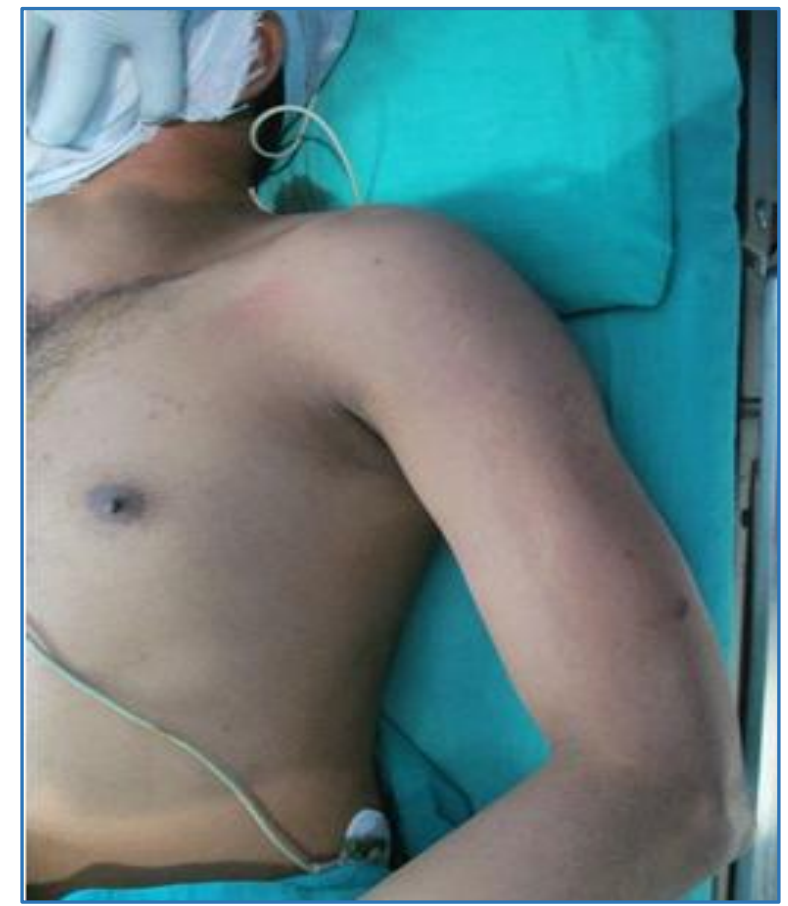

Figure 2: Position of the Patient on the OT Table

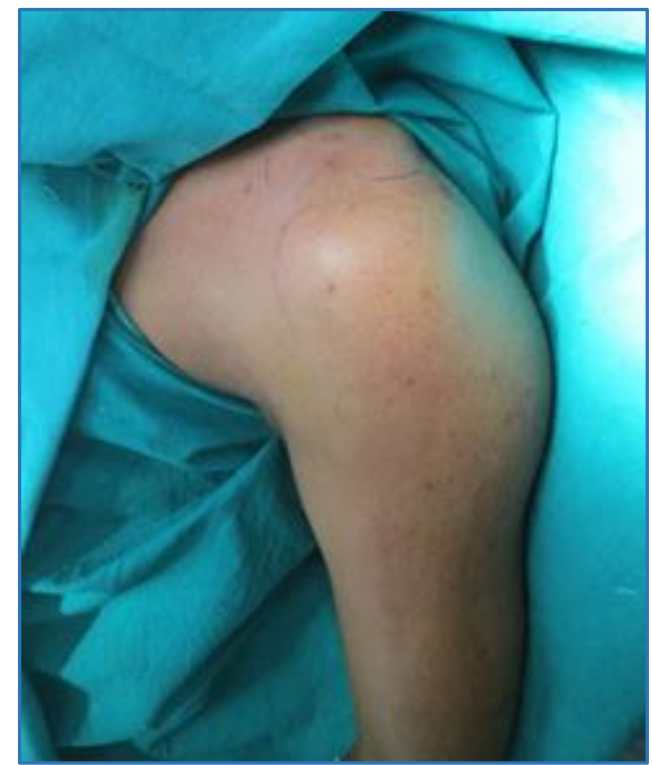

Figure 3: Marking of Bony Land Marks

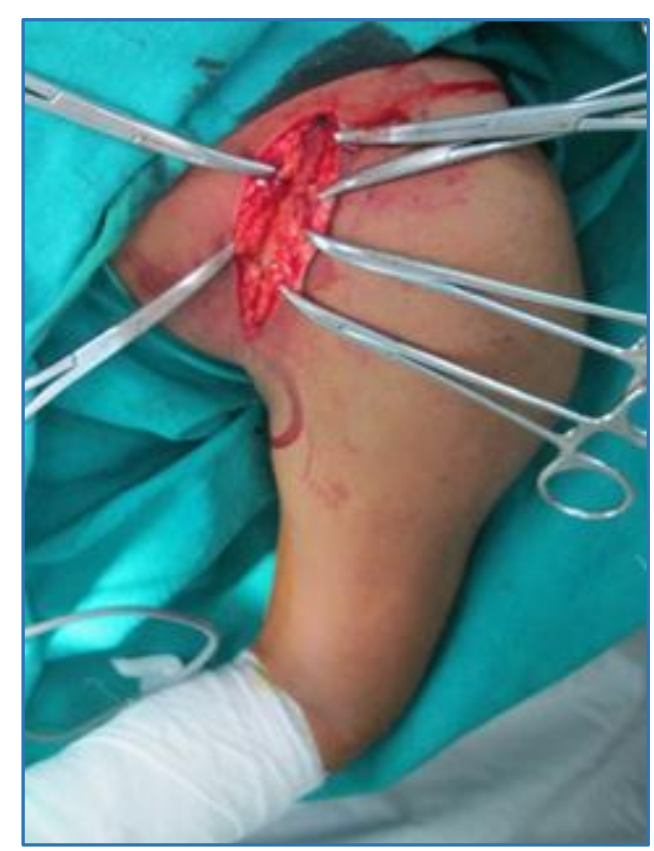

Figure 4: Deltopectoral Approach

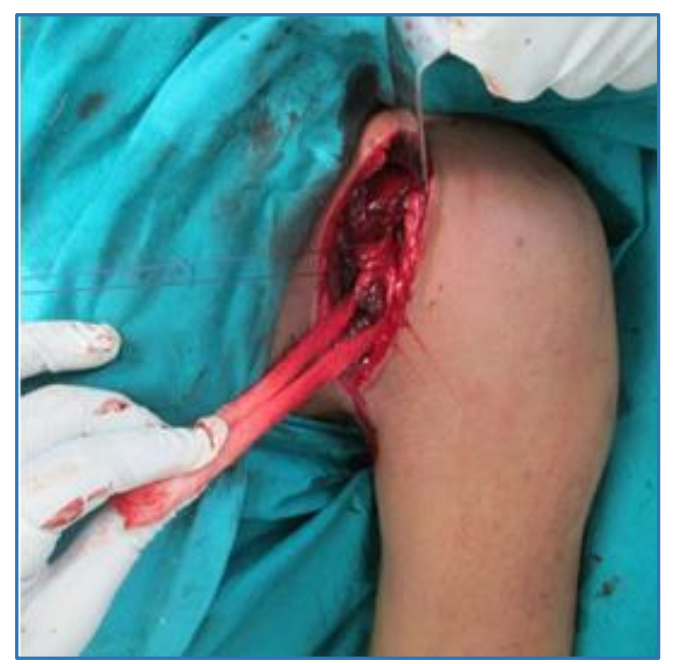

Figure 5: Osteotomy of the Tip of the Coracoid Process 


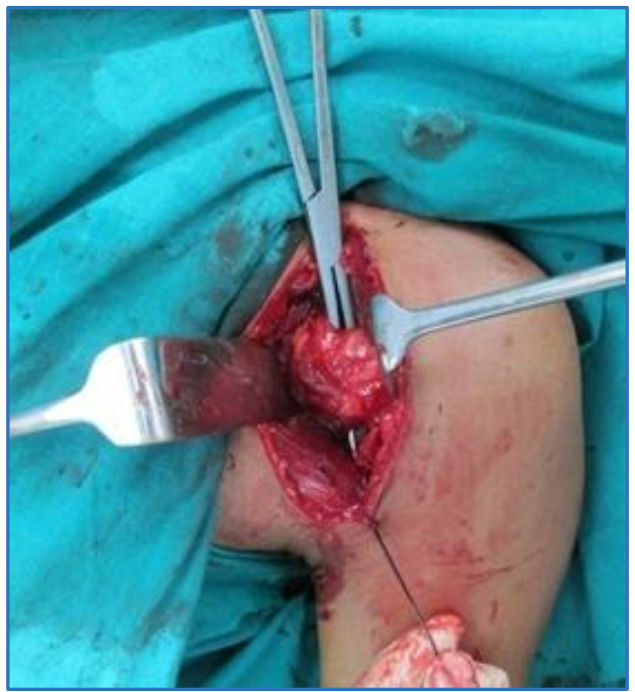

Figure 6: Tunnel Developed between Subscapularis and the Capsule of the Shoulder Joint

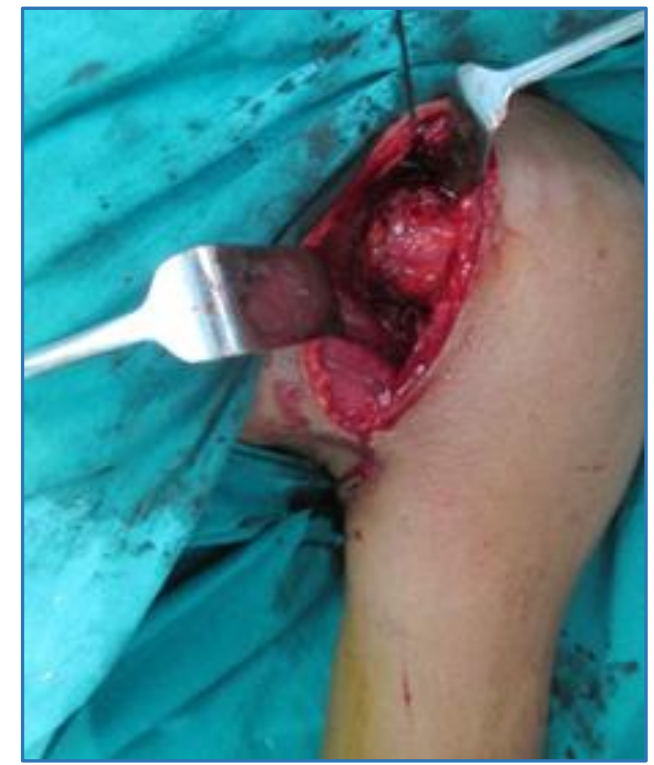

Figure 7: Re-Routing of the Tip of the Coracoid Process behind the Subscapularis Muscle

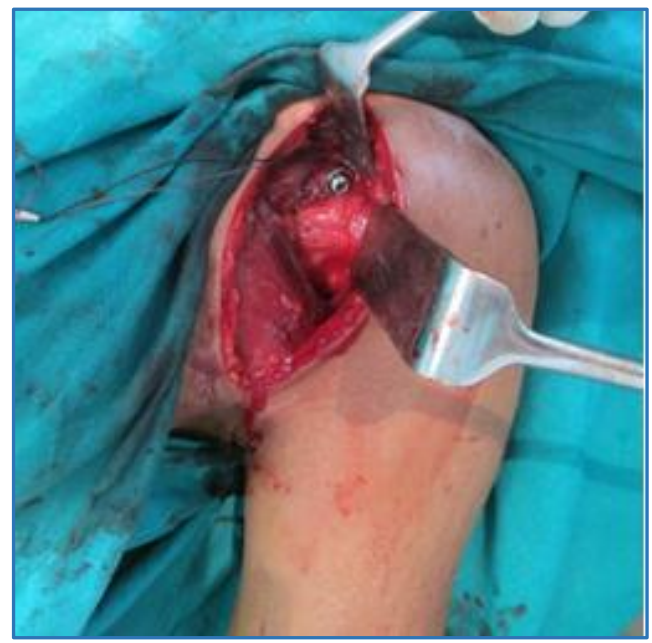

Figure 8: Fixing of the Tip of the Coracoid Process to the Body of the Coracoid with a Lag Screw

\section{Post-Operative Management}

The arm was immobilised by the side of chest with the shoulder in internal rotation. The position of the screw was assessed using post-op radiographs (Fig. 9). At two weeks, pendulum shoulder exercises were started after removal of the sutures. At three weeks, active-assisted shoulder mobilisation was started aiming to achieve full shoulder movements at 8 weeks (Fig. 10 and 11).

The patients were evaluated every 12 weeks during the first year. Outcome was evaluated using the Burkhead and Rockwood criteria; a score of 90 to 100 was considered excellent, 70 to 89 good, 40 to 69 fair and $\leq 39$ poor. ${ }^{1}$

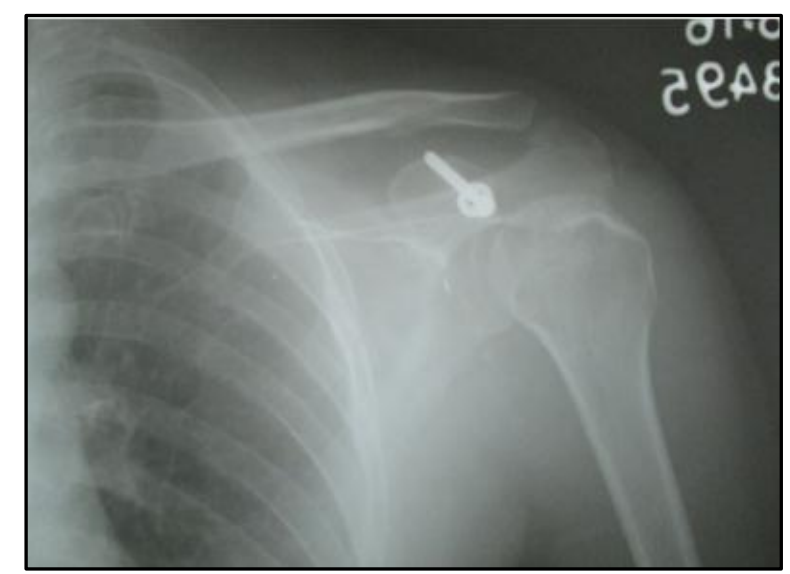

Figure 9: Post-Op Radiograph

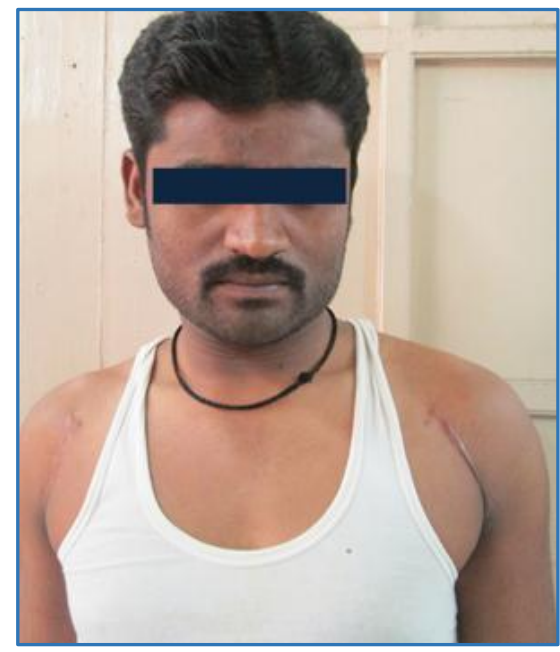

Figure 10: Bilateral Repair Done

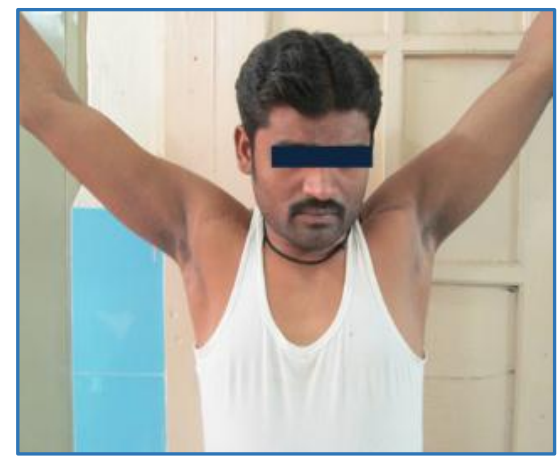

Figure 11: Post-Op Abduction on Both Sides 


\section{RESULTS}

All the patients are male in the study.

The mean follow-up period was 20 years. Outcome was excellent in 35 patients, one had poor outcome. One patient had recurrence of the anterior dislocation. No patient had evidence of loosening, migration of screw in the coracoid process or evidence of glenohumeral arthritis.
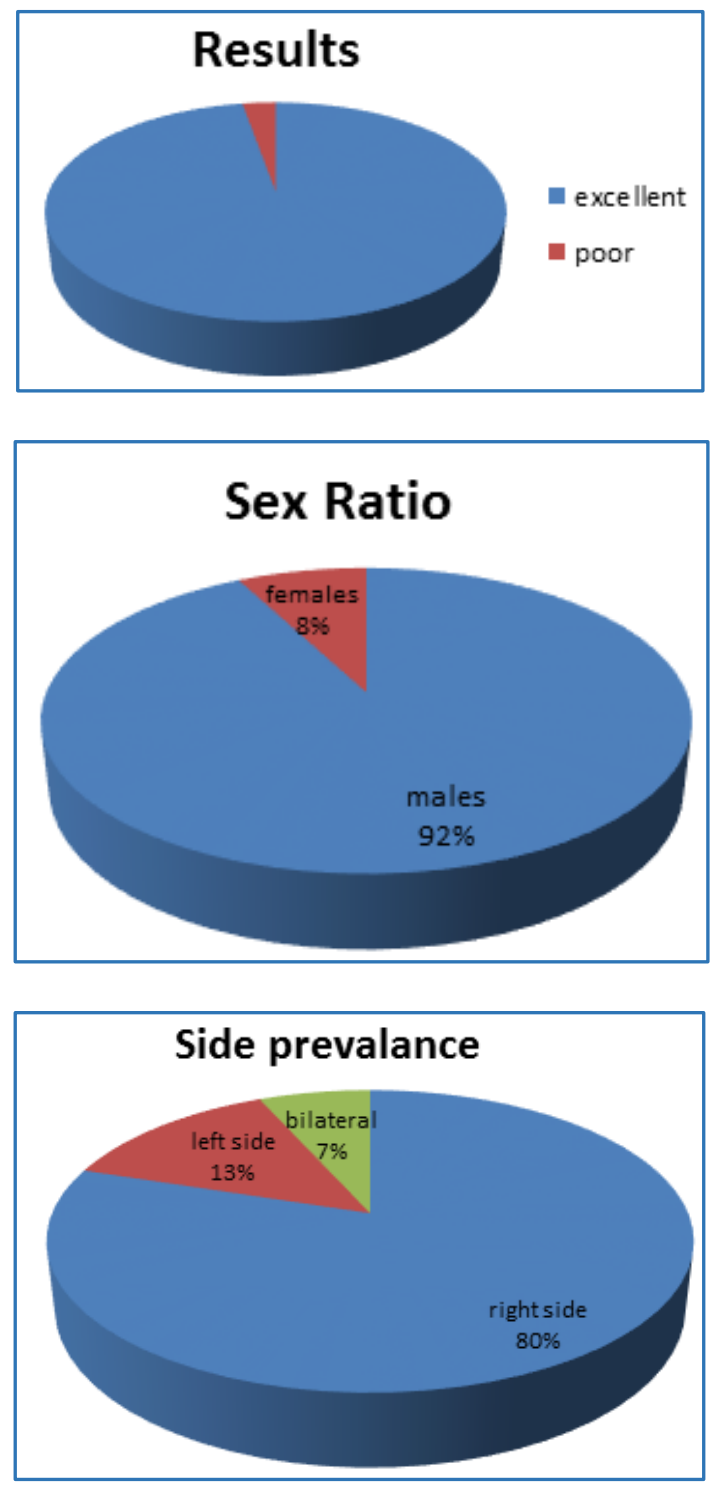

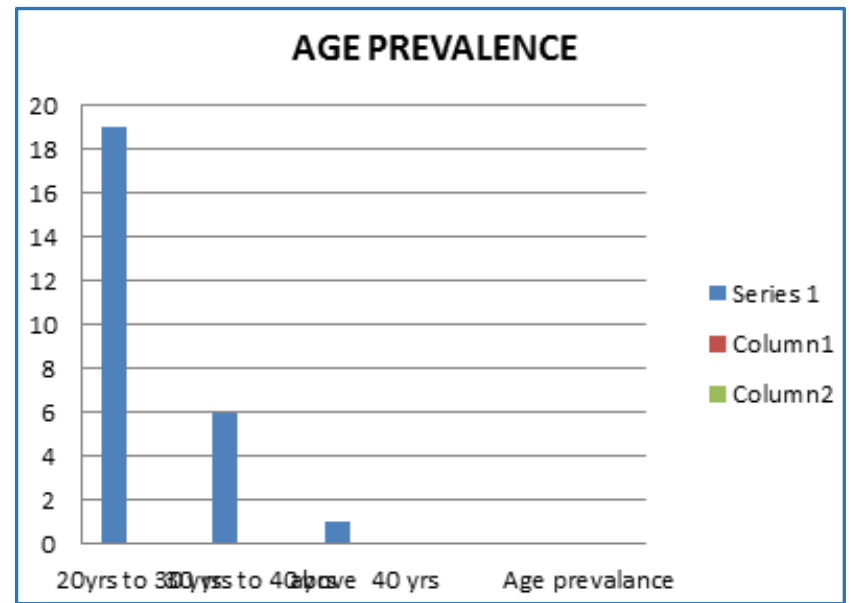

\begin{tabular}{|c|c|}
\hline Outcome Score* Function & \\
\hline $\begin{array}{l}\text { No limitation in work, slight limitation in throwing } \\
\text { baseball, serving forcefully in tennis or swimming, } \\
\text { crawl, stroke can throw football normally }\end{array}$ & 35 \\
\hline $\begin{array}{c}\text { Moderate limitation in overhead work, throwing } \\
\text { baseball and football, swimming, crawl, stroke or } \\
\text { serving tennis }\end{array}$ & 20 \\
\hline $\begin{array}{l}\text { Marked limitation in throwing in all sports, unable to } \\
\text { work with arm overhead }\end{array}$ & 0 \\
\hline $\begin{array}{l}\text { Pain } \\
\text { None }\end{array}$ & 10 \\
\hline Moderate & 5 \\
\hline Severe & 0 \\
\hline $\begin{array}{c}\text { Stability } \\
\text { Negative apprehension test, no subluxation }\end{array}$ & 30 \\
\hline $\begin{array}{l}\text { Negative apprehension test, but discomfort with arm } \\
\text { in position of abduction and external rotation }\end{array}$ & 15 \\
\hline Positive apprehensive test and sense of subluxation & 0 \\
\hline $\begin{array}{c}\text { Range of Motion } \\
\text { Full } \\
\end{array}$ & 10 \\
\hline $25 \%$ loss of motion in any plane & 5 \\
\hline$>25 \%$ loss of motion in any plane & 0 \\
\hline
\end{tabular}

\begin{tabular}{|c|c|c|c|c|c|}
\hline Author & Year & No. of Shoulders & Recurrence & Followup & Comment \\
\hline Conforty $^{5}$ & 1980 & 17 & Nil & Mean 6 years & Excellent \\
\hline Ha Eri GB $^{4}$ & 1986 & 26 & Nil & Mini 2 years & Excellent \\
\hline Yozo S etal $^{3}$ & 1999 & 63 & $3.1 \%$ & Mean 50 months & Excellent \\
\hline $\begin{array}{c}\text { Chattarjee ND et al } \\
\begin{array}{c}\text { Zamora-Navas P } \\
\text { et al }\end{array}\end{array}$ & 2002 & 46 & One subluxation & Mean 88 months & Excellent \\
\hline Li SP et al & 2001 & 27 & $20 \%$ & Mean 13.3 years & $\begin{array}{c}\text { Attractive, but might } \\
\text { be avoided }\end{array}$ \\
\hline Han TY et al & 2008 & 15 & Nil & $\begin{array}{c}\text { Mean 4 years 5 } \\
\text { months }\end{array}$ & Simple and effective \\
\hline Garg et al & 2011 & 48 & One subluxation & $\begin{array}{c}10 \text { months to } \\
4.5 \text { yrs. }\end{array}$ & Simple and effective \\
\hline $\begin{array}{c}\text { Our Study } \\
\text { Ravindranath et al }\end{array}$ & $\begin{array}{c}\text { From May } \\
\text { May 2015 to }\end{array}$ & 36 & 1 & 58 months & Simple and effective \\
\hline \multicolumn{2}{|c|}{ Table 2 } & $\begin{array}{c}\text { Excellent and } \\
\text { reproducible } \\
\text { procedure }\end{array}$ \\
\hline
\end{tabular}




\section{DISCUSSION}

Treatment for recurrent anterior dislocation of shoulder should provide an active corrective force that pushes the humeral head into the glenoid fossa. Surgical treatments for recurrent anterior dislocation of the shoulder include passive interventions using capsule ligamentous repair like Open or Arthroscopic Bankart repair or bone block to create barriers and active interventions using muscle action like Bristow's operation, ${ }^{6}$ where the tip of coracoid along with the conjoined tendons is fixed to the anterior glenoid rim through the subscapularis, but has many disadvantages as shortening of the subscapularis muscle, internal rotation contracture, limited external rotation, non-union of the coracoid process to the neck of the scapula and injury of the musculocutaneous nerve. Magnuson and Stack operation, transferred subscapularis muscle laterally to the greater tuberosity to overcome its weakness, but has significant decrease of the amount of external rotation.

The Putti-Platt procedure ${ }^{7}$ produces limitation of the external rotation and abduction of the shoulder joint. The failure rate was reported to be $20 \%$ Arthroscopic repair ${ }^{8}$ of unidirectional shoulder instability and inferior compared to traditional open repair. The risk of increased rates of recurrent instability currently appears to outweigh the potential benefits of arthroscopic repair. The technique of Modified Boytchev $^{9,10}$ has many advantages as it is safe, easily reproducible, cost effective and provides immediate strong dynamic stability to the shoulder joint. This will hold the humeral head posterior when the arm is abducted and externally rotated as in overhead activity.

\section{The Advantages of Modified Boytchev $3,5,3,11,12,13,14$ Procedure are}

The re-routed muscle bellies to lie more directly in contact with the joint capsule and humeral head, so that their active contraction exerts a strong control on the anterior exertion of the humeral head, thereby balancing the deforming forces of dislocation.

The modified Boytchev procedure increases the pressure between the humeral head and subscapularis tendon, and thus increases proprioceptive stimuli in the subscapularis tendon, which accelerates the protective reflex needed to prevent shoulder dislocation.

The increased muscle bulk of the subscapularis, coracobrachialis and the short head of biceps augments the bracing effect over the antero-inferior aspect of the glenohumeral joint.

The literature suggests the recurrence rates after the Bankart's procedure 6\%, Putti-Platt procedure $20 \%$, Magnuson-Stack procedure $7 \%$ and Bristow procedure $13 \%$ with restriction of external rotation and glenohumeral arthritis in long-term follow-up; 8 - 10 years the Boytchev procedure achieves comparable results with lower recurrence rate, minimal restriction of external rotation and no glenohumeral arthritis.

Literature on Boytchev procedure and our study indicates that Modified Boytchev procedure is more beneficial. Studies show excellent results. Operative procedure was originally described in Bulgarian language and that made it inaccessible in most of the countries. The First Scandinavian-Japanese Shoulder Congress held in 1989 and thereafter successive meetings made this procedure known to the Asian countries. Since 1990 till date, most studies from this part of the world have given excellent results and valid scientific study has led us to recommend Modified Boytchev is an efficacious operative procedure for treatment of recurrent anterior dislocation of shoulder. The dynamic contribution of the conjoined tendon after the Boytchev procedure in a cadaveric study has been reported.

\section{CONCLUSION}

The Modified Boytchev procedure is a simple and an easily reproducible surgical treatment for Recurrent Anterior Shoulder dislocation with proper exclusion criteria. It is also very cost effective procedure.

\section{REFERENCES}

[1] Burkhead WZ, Rockwood CA. Treatment of instability of the shoulder with an exercise program. J Bone Joint Surg Am 1992;74(6):890-6.

[2] Ha'Eri GB. Boytchev procedure for treatment of anterior shoulder instability. Clin Orthop Relat Res 1986;206:196-201.

[3] Garg AK, Ayan S, Keshari V, et al. Modified Boytchev procedure for treatment of recurrent anterior dislocation of shoulder. Indian J Orthop 2011;45(4):33640.

[4] DePalma AF, Cooke AJ, Prabhakar M. The role of subscapularis in recurrent anterior dislocations of the shoulder. Clin Orthop Relat Res 1967;54:35-49.

[5] Shibata Y, Honjo N, Shinoda T, et al. Pressure between the humeral head and the subscapularis tendon after the modified boytchev procedure. J Shoulder Elbow Surg 2004;13(2):170-3.

[6] Hovelius L, Akermark C, Albrektsson B, et al. BristowLaterjet procedure for recurrent anterior dislocation of the shoulder. A 2-5 year follow-up study on the results of 112 cases. Acta Orthop Scand 1983;54(2):284-90.

[7] Fredriksson AS, Tegner Y. Results of the putti-platt operation for recurrent anterior dislocation of the shoulder. Int Orthop 1991;15(3):185-8.

[8] Lenters TR, Franta AK, Wolf FM, et al. Arthroscopic compared with open repairs for recurrent anterior shoulder instability. A systematic review and metaanalysis of the literature. J Bone Joint Surg Am 2007;89(2):244-54.

[9] Conforty B. The results of the Boytchev procedure for treatment of recurrent dislocation of the shoulder. Int Orthop 1980;4(2):127-32.

[10] Jiang LS, Cui YM, Zhou ZD, et al. Stabilizing effect of the transferred conjoined tendon on shoulder stability. Knee Surg Sports Traumatol Arthrosc 2007;15(6):800-5.

[11] Reddy GV, Prasad JS. Ha'eri-Chari's operative procedure for treatment of recurrent dislocation of shoulder. Indian J Orthop 1997;31(1):53-7.

[12] Chatterjee ND, Nath C, Pal AK, et al. Modified Boytchev procedure for the treatment of recurrent anterior dislocation of the shoulder. Int Orthop 2002;26(1):7-9.

[13] Navas ZP, Verdera BA, Garcia PJ, et al. Long-term results of the boytchev procedure for the treatment of recurrent dislocation of the shoulder. Acta Orthop Belg 2001;67(3):233-5.

[14] Dalsgaard HL, Gothgen CB, Hoogmartens MJ. The boytchev procedure for recurrent anterior dislocation of the shoulder. A controversial technique. Acta Orthop Belg 2000;66(3):248-50. 